\title{
The Effect of Positive Parenting Program on Interaction of Mother and Deaf Child
}

\author{
Mohammad Ashori ${ }^{1 *}$ and Seyyedeh Somayyeh Jalil Abkenar ${ }^{2}$ \\ ${ }^{1}$ Department of Psychology and Education of Children with Special Needs, Faculty of Education and Psychology, University of Isfahan, Iran \\ ${ }^{2}$ Department of Psychology and Education of Exceptional Children, University of Tehran, Iran
}

*Corresponding author: Mohammad Ashori, Department of Psychology and Education of Children with Special Needs, Faculty of Education and Psychology, University of Isfahan, Iran.
Received Date: August 12, 2019

Published Date: September 06, 2019

\begin{abstract}
There is growing interest in the interaction of mother and deaf child. A deaf child threatens interaction and relationships among family members. So, it is important to intervention suitable training programs for promotion of interaction of mother and deaf child. Hence, the present study examined the effect of positive parenting program (Triple-P) on the interaction of mother and deaf child. The present study was a quasi-experimental research with pre-test and post-test design and a control group. Thirty-two mothers of deaf children participated in this study. The subjects were selected via multistage cluster sampling method. They were divided randomly into an experimental and control group. Each group consisted of 16 mothers. The experimental group participated in the Triple-P within 12 sessions, and each session lasted 70 minutes ( 2 days a week for 6 weeks), but the control group did not participate in this program and remained in waiting list. The instrument was done using the parent-child relationship scale of Piyanta. The obtained data were statistically analyzed by MANCOVA. Findings of the present research showed that Triple-P intervention had a significant impact on conflict, closeness, dependency, and positive relationship of mother and deaf child. These findings emphasize the need to consider the Triple-P for improvement the interaction of mother and deaf child. Comprehensive understanding of conflict, closeness, dependency, and positive relationship of mother and deaf child is needed to provide impactful interventions for Triple-P.
\end{abstract}

Keywords: Deaf child, Interaction, Positive parenting program

\section{Introduction}

Children with special needs can have a main impact on their family [1,2]. A deaf or hard of hearing person in a family may affect all areas of family life [3]. Usually, a deaf child threatens interaction and relationships among family members [4]. A deaf child can have more impact on the interaction of mother than father and siblings. Mothers of deaf children have more conflict, dependency and negative relationship [5]. These issues threaten their relations and interaction. Although, issues such as life quality, psychological wel being, marital happiness, and informal and formal supports impact on interaction of mother and deaf child, however the effect of deafness in child should not to be ignored on interaction of parent-child and psychological wellbeing of parents [6]. Parenting skill can increase a sense of self-efficacy and self-control. and improve perceived wellbeing and interaction of parent-child. Thereby the aim of Triple-p is improvement the skill of the parents and interaction with their children [7]. To be deaf or hearing impairment, often places a person in a difficult place somewhere between the world of the hearing and the world of the deaf [8]. Deafness is associated with changes in behavior and interaction with others [9]. A deafness can put a person at risk for isolation and communication problems [8]. The presence of deaf children in the family affects the quantity and quality of parental relationships and the interaction of family members [10]. Deafness increases the likelihood of psychological disorders due to difficulty in the communication problems. Deafness leads to withdrawal, rejection feeling, lower life quality and social activities reduction [11-13]. Deaf children impact on relations and quality of life among family members [14]. Also, Deafness have negative effect on the motherchild interaction [6].

A key factor of development for each person, whether deaf or hearing, is the ability to social interaction [15]. Improvement parenting is a common method to enhancing the interaction of 
parent-child [7]. Family interaction in general and the parentchild interaction in particular have a pervasive effectiveness on the physical, cognitive, psychological, and social dimensions of children development. Many problems in the interaction among family members are related to disturbance in family function and breakdown of family relations [12]. The risk factors in family such as family conflict, dependency to family and poor parenting strongly effect on development of children [16]. Pay attention to the interaction and relation of mother-child with developmental disabilities, they show more conflict and dependency compared with mothers of normal children. [17-19]. In particular, lack of a positive and warm relations with parents; inconsistent discipline; harsh, rigid or inflexible practices; insecure attachment; conflict with children and inadequate supervision; breakdown and marital conflict; and psychopa thology in parent (particularly depression in the mothers) increase the risk of children's developing behavioral and emotional problems [20]. Also, other factors may play role in the attachment style among mothers and children [16, 20]. The present study describes the comprehensive model of program parenting, named positive parenting program that aims to the better equip mothers and fathers in their child training role.

\section{Positive Parenting Program}

Parenting refers to special methods and behaviors used in the rearing of children that influence child outcomes. Also, parents play an important role in behavioral and psychological well-being in their children [3]. Positive Parenting Program (Triple-P) is a type of behavioral family program based on principles of social-learning. it was developed as a multilevel, comprehensive, and preventionoriented system for support parenting [21]. In the other word, Triple-P is a parent's training program that is designed by Sanders pay attention to social learning theory of Bandura based on family intervention $[7,22]$. Triple-P is an Australian program based on cognitive, behavioral and developmental concepts and principles [23]. This comprehensive intervention can be used for improvement of emotional and behavioral problems in the children and relationship of mothers and children, with providing information about different needs of mother and child, interaction of mother and child, parenting styles and family function [24]. One purpose of the Triple-P intervention is to suggest the minimally enough support that a family need [22]. Use of Triple-P is suggested for parent of exceptional children from birth to 16 years [25,26], which focused on relationship with children, control and management of behavior, and also improved development of children through parent instruction and helps the parents to mental health and obtain the self-control parenting skills and sense of social competency [7]. This training program follows these goals: increase of self-efficacy, knowledge, self-confidence and interaction of parent-child. [24,27].

Research with deaf people and their families and communities has focused on the difficulties and challenges that are faced $[4,28]$. Deaf children, regardless of where they live, require the similar intervention to maximize developmental outcomes [5,29]. Many studies were done for identification and solving these issues but does not mean that all issues of these individuals can be identified [22]. Some studies have been done about the effectiveness of
Triple-P on relationships of mother-child in different age and groups. For example, the research findings of Ashori M et al. [2] showed that Triple-P intervention had positive and significant effect on depression, social dysfunction, anxiety, somatic symptoms and mental health in mothers of the children with intellectual disability. Also, the research finding of Ruane A and Carr A [22] showed that Triple-P intervention was an effective program for reduction of behavioral problems in children and improvement of parental relationship, parenting satisfaction, parenting selfefficacy, parenting style and parental adjustment. Study result of Lohan A, et al. [27] indicated that Triple-P was a positive and effective program for parental self-efficacy, parenting stress, and interaction in parent-child. Rostami M, et al. [30] documented that positive thinking skills training had a positive effect on reported levels of happiness in deaf adolescents. Study finding of Kleefman M, et al. [23] showed that the Triple-P intervention led to decrease of psychological problems in parents and increase of interaction of parent-child with borderline to intellectual disability.

The study result of Glazemakers I and Deboutte D [31] indicated that Triple-P intervention led to reduce in child psychological distress, conduct problems and maladaptive parenting. The research finding of Chu J, et al. [32] indicated that parenting intervention led to positive and significant on mental health of parents. The study finding of Metzler C, et al. [33] showed that the use of media in the parenting program led to a positive and significant effect on interaction of parents and their general health. The study results of Fujiwara T, et al. [21] indicated that the Triple-P intervention led to reducing behavior problems in children, changing influencing parenting and adjustment dysfunctional parenting practices among families. Many fathers and mothers of deaf children need to parenting program to learn skills and strategies in order to control and manage children behavior problems and parent-child relations [4]. The parent-child interaction and parenting have been identified as important program to support of mothers and children self-efficacy and mother-child interaction, yet a few parenting interventions have been designed for parents [27]. The findings of many researches indicated that Triple-P intervention had a significant impact on improvement of the parenting styles, family interaction and behavioral difficulties in the exceptional children. It is likely, there was no evidence indicating changes in interaction of mother and deaf child. At seems, parents of deaf children face more problems in interaction with their children. On the other hand, this research very important for sensitivity of parenting in the mothers of deaf children. Therefore, at seems parenting instruction that considers these main factors can play vital role on interaction of mother and deaf child.

\section{Purpose of the Study}

The purpose of the present study was to the effect of Triple-P on interaction of mother and deaf child.

\section{Questions}

This research guided by two question: (1) Is there a difference between interaction of mother and deaf child in the experimental and control group? (2) Is there a difference between conflict, closeness and dependency in the experimental and control group? 


\section{Methods}

The present study was a quasi-experimental research with pretest and post-test design and a control group.

\section{Participants}

Statistical population included mothers of deaf children aged 32 to 41 years that their children enrolled in exceptional schools in Tehran, Iran in academic year 2018-19. The subjects were selected via multistage cluster sampling method. In the first step, 2 schools selected randomly from the 15 deaf elementary schools and in the second step, 32 mothers of deaf children selected from these deaf schools. This study was approved by the Exceptional Educational Organization Ethics Committee in Tehran, Iran. The importance of study was explained to participants to make assure that the study has no harm to them. Also, written informed consent was obtained from all participants, after receiving approval from the school principals and Exceptional Educational Organization director.

The Inclusion criteria for participant were living with husband and children; age range of 32-41 years; having a prelingually deaf child with sensory-neural hearing impairment in both ears in the range of 50 to 80 decibels $(\mathrm{dB})$, using hearing aids in both ears, IQ between 90-100, and aged 8-10 years. Exclusion criteria were participating in similar interventions, and presence of each kind of physical, motor and sensory disorder in their children, expect deafness. Subjects had low socio-economic state and matched based on this condition. Also, income of their families was under average. In the next step, subjects were divided into experimental and control groups and each group consisted of 16 peoples. In this research, there were an experimental group who participated in Triple-P intervention, while control group did not participate this. Base on ethical issues, after the end of study, control group participated in Triple-P workshop in two days.

\section{Tool}

Parent-child relationship scale (PCRS): The PCRS was made by Piyanta in 1994, which consists of 33 items and 3 subscales including closeness (10 items), conflict (17 items), and dependence (6 items). This scale was scored based on Likert, from 1 to 5 . The conflict and dependency subscales was reverse-coded and the conflict, closeness, dependency subscales were combined to obtain a total mean of score for each subject. Higher scores indicate warmer parental interaction. Internal consistencies for the total scale were 0.62 . Cronbach's coefficients were $0.84,0.69,0.46$, and 0.80 with respect to the conflict, closeness, dependency and total positive relationship, respectively. In Iran, Ashori M, et al [34] reported the internal consistencies for the total scale was 0.71 and Cronbach's coefficients were $0.79,0.72,0.68$, and 0.81 with respect to the conflict, closeness, dependency and total positive relationship, respectively [34].

\section{Procedure}

Subjects were selected from two deaf schools of Exceptional Educational Organisation. The importance of present research was explained to participants to make assure that the project has no harm to them. Also, informed consent was obtained from subjects. To examine mother-child relationship of experimental and control group, the PCRS of Piyanta was completed by participant as pretest in writing method. Prior to intervention, subjects were not participated to each type of parenting program. Also, mother-child relationship was inappropriate based on PCRS.

The length of time for interval between pre-test and post-test was about 2 months. To Triple-P training to the intervention group was used role playing, discussion, modelling, behavioral rehearsal and video demonstration.

\section{Educational intervention}

The intervention which was used in the present research was Triple-P. This intervention was the Australian version which was developed by Sanders. The experimental group participated in Triple-P within twice a week at 12 sessions (each lasting about 70 minutes). The sessions content of Triple-P is showed in (Table 1).

Table 1: The sessions content of Triple-P.

\begin{tabular}{|c|c|c|}
\hline Sessions & Aims & Context of Each Session \\
\hline 1 & Group positive parenting & $\begin{array}{l}\text { Getting to know each other, Awareness of purpose of the program, and the rules of the group, Discus- } \\
\text { sion about the cause of the problematic's behavior. }\end{array}$ \\
\hline 2 & Group positive parenting & $\begin{array}{l}\text { Encouraging parents to observe their child's behavior, Determine goals for modification behavior in } \\
\text { own child. }\end{array}$ \\
\hline 3 & Promoting child development & $\begin{array}{l}\text { Strategies for establishing positive relationships with the child (such as talking to the child, having } \\
\text { fun, allocating useful time to the child), Practice and role playing in small groups. }\end{array}$ \\
\hline 4 & Promoting child development & $\begin{array}{l}\text { Methods to increase positive behaviors (positive reinforcements, token economy, contingency con- } \\
\text { tracting with providing fun activities). }\end{array}$ \\
\hline 5 & Promoting child development & $\begin{array}{l}\text { Methods to conduct appropriate behaviors (shaping and chaining) and its maintenance (continuous } \\
\text { and intermittent reinforcements). }\end{array}$ \\
\hline 6 & Promoting child development & $\begin{array}{l}\text { Strategies such as casual learning, a technique for asking, saying, doing to parents for teaching new } \\
\text { behaviors and skills to the own child. }\end{array}$ \\
\hline 7 & $\begin{array}{l}\text { Ineffective behavior manage- } \\
\text { ment }\end{array}$ & $\begin{array}{l}\text { Discussion about the negative consequences of punishing, Training strategies about misbehavior in } \\
\text { child such as legislation, direct discussion, direct and indirect instruction, and behavior ignoring. }\end{array}$ \\
\hline 8 & $\begin{array}{l}\text { Ineffective behavior manage- } \\
\text { ment }\end{array}$ & Positive methods for reduction of inappropriate behaviors (type of differential reinforcements). \\
\hline 9 & $\begin{array}{l}\text { Ineffective behavior manage- } \\
\text { ment }\end{array}$ & $\begin{array}{l}\text { Effective coping with inappropriate behaviors including logical consequence, extinction, deprivation } \\
\text { and time out. }\end{array}$ \\
\hline
\end{tabular}




\begin{tabular}{|c|c|c|}
\hline 10 & $\begin{array}{l}\text { Ineffective behavior manage- } \\
\text { ment }\end{array}$ & $\begin{array}{c}\text { Combining learned strategies, Use of daily follow-up program, behavioral correction program and } \\
\text { behavioral chart. }\end{array}$ \\
\hline 11 & Plan ahead & $\begin{array}{c}\text { Identify the high-risk situations and the usage of learned strategies in high-risk situations at home } \\
\text { and outside. }\end{array}$ \\
\hline 12 & Plan ahead & Providing guidelines for the survival and Stability of the family. \\
\hline
\end{tabular}

\section{Statistical analysis}

The obtained data was statistically analyzed by descriptive and inferential statistics. To examination of the effect of Triple-P on conflict, closeness, dependency, and positive relationship of mother and deaf child in experimental and control group was used MANCOVA through using SPSS software (SPSS Inc., Chicago, IL, USA).

\section{Results}

Table 2: Demographic information of deaf children and their mothers.

\begin{tabular}{|c|c|c|c|c|c|c|c|c|c|c|c|c|}
\hline \multirow{2}{*}{ Group } & \multirow[b]{2}{*}{$\mathrm{n}$} & \multicolumn{6}{|c|}{ Children } & \multicolumn{5}{|c|}{ Mothers } \\
\hline & & Age & M & SD & IQ & M & SD & Age & M & SD & $\mathrm{t}$ & $\mathrm{p}$ \\
\hline Experimental & 16 & 10-Aug & 9.07 & 0.39 & $90-100$ & 96.33 & 2.27 & $32-41$ & 37.12 & 1.81 & 1.13 & 0.11 \\
\hline Control & 16 & 10-Aug & 9.12 & 0.37 & $90-100$ & 96.15 & 2.08 & $32-41$ & 36.94 & 1.87 & & \\
\hline
\end{tabular}

Demographic information of deaf children and their mothers in experimental and control group are presented in (Table 2).

As presented in Table 2, the mean ages of mothers in experimental and control group were 37.12 and 36.94. The finding of t-test showed that there was no significant difference in age into two groups $(\mathrm{P}=0.11)$ Table 3 shows mean and standard deviation of PCRS in three subscales (conflict, closeness and dependency) and positive relationship of mother-child in pre-test and posttest of the experimental and control groups. As shown in Table 3, scores mean of PCRS in all subscales and positive relationship in pre-test and post-test of the experimental and control groups. The study questions focused on difference in positive relationship and its subscales in participants into experimental and control group. Kolmogorov-Smirnoff (K-S) test approved the normality of study variables, Box's test confirmed variance-covariance equality and assumption of variance equality confirmed using Leven's test $(\mathrm{P}>0.05)$. Therefore, MANCOVA test can used. PCRS calculated via Wilk's Lambda test, which findings indicated that experimental and control group had significant difference, at least in a variable with eta square $(\eta 2), \% 71(\mathrm{~F}=83.27, \mathrm{P}=0.001)$. In order to examine this difference, MANCOVA test was used, which results are showed in (Table 4).

Table 3: Mean and standard deviation of PCRS in pre-test and post-test.

\begin{tabular}{|c|c|c|c|c|c|c|}
\hline \multirow{10}{*}{ PCRS } & \multirow[t]{2}{*}{ Variable } & \multirow[t]{2}{*}{ Stage } & \multicolumn{2}{|c|}{$\begin{array}{l}\text { Experimental } \\
\text { Group }\end{array}$} & \multicolumn{2}{|c|}{$\begin{array}{c}\text { Control } \\
\text { Group }\end{array}$} \\
\hline & & & Mean & SD & Mean & SD \\
\hline & \multirow{2}{*}{ Conflict } & Pretest & 53.08 & 2.19 & 54.62 & 2.65 \\
\hline & & Posttest & 42.61 & 2.2 & 53.34 & 2.24 \\
\hline & \multirow{2}{*}{ Closeness } & Pretest & 20.52 & 1.07 & 20.19 & 1.11 \\
\hline & & Posttest & 25.67 & 1.03 & 20.68 & 1.19 \\
\hline & Dependency & Pretest & 16.92 & 0.92 & 16.8 & 1.03 \\
\hline & \multirow{3}{*}{$\begin{array}{l}\text { Positive } \\
\text { relationship }\end{array}$} & Posttest & 12.35 & 0.97 & 16.44 & 0.97 \\
\hline & & Pretest & 67.5 & 2.88 & 67.12 & 3.04 \\
\hline & & Posttest & 81.29 & 2.81 & 67.01 & 3.01 \\
\hline
\end{tabular}

Table 4: Results of MANCOVA.

\begin{tabular}{|c|c|c|c|c|c|c|c|}
\hline \multicolumn{2}{|c|}{$\begin{array}{c}\text { Dependent } \\
\text { Variable }\end{array}$} & SS & df & MS & F & P & 2 \\
\hline \multirow{3}{*}{ PCRS } & Conflict & 40.18 & 1 & 40.18 & 16.94 & 0.001 & 0.59 \\
\cline { 2 - 8 } & Closeness & 39.64 & 1 & 39.64 & 12.61 & 0.001 & 0.56 \\
\cline { 2 - 8 } & Dependency & 34.05 & 1 & 34.05 & 11.52 & 0.001 & 0.54 \\
\cline { 2 - 8 } & $\begin{array}{c}\text { Positive } \\
\text { relationship }\end{array}$ & 41.37 & 1 & 41.37 & 16.17 & 0.001 & 0.55 \\
\hline
\end{tabular}

In the present analysis, pre-test variables were moderated because of correlation with post-test. As table 4 showed intervention had significant effect on post-test scores $(\mathrm{P}<0.05)$. Based on eta square $(\eta 2)$, it can be explained that $\% 59, \% 56, \% 54$ and $\% 55$ of the variation in each one of the variables of conflict, closeness, dependency and positive relationship of PCRS, respectively are for the effect of Triple-P on interaction of mother-child.

\section{Discussion}

The findings of present research indicated that Triple-P had significant effect on conflict, closeness, dependency, and positive relationship of mother and deaf child. Finding of present research were inconsistent with research finding of Wilson et al., [35] that stated effect of Triple-P training on mother's interaction was moderate and father's interaction were lower and did not significant difference with control group. Finding of the present research were consistent with research result of Ashori M, et al. [2] that showed Triple-P intervention had significant and positive effect on anxiety, depression, somatic symptoms, social dysfunction and mental health in mothers of children with intellectual disability. Finding of the present study were consistent with research findings of Ruane \& Carr [22] that concluded Triple-P intervention was an $\mathrm{p}$ for reduction of behavioral problems in children and improvement of parental relationship, parenting satisfaction, parenting self-efficacy, parenting style and parental adjustment. Also, similar to research result of Lohan Ac et al. [27] that indicated Triple-P intervention was a positive program for parenting stress, parental self-efficacy and interaction of parent-child. Finding of the present research was similar to findings of study of Kleefman M, et al. [23] that stated the 
Triple-P led to decrease of psychological problems in parents and increase of interaction of parent and deaf child. Also, finding of the present research were consistent with research result of Metzler C, et al. [33] that showed the use of group media in parenting program led to a positive and significant effect on interaction of parents and their children.

For explain the inconsistency of the research results of Wilson P, et al. [35] with finding of present research, it can be said that a meta-analysis and systematic review of Triple-P intervention by Wilson et al. consisted some of methodological, conceptual and interpretational inappropriate that render the conclusions of their study problematic [2,24]. Moreover, Ruane \& Carr [22] by a meta-analysis and systematic review about Triple-P not confirmed research result of Wilson et al. On the other hand, Sanders MR, et al. [25] said that Wilson P, et al. [35] concluded from a limited sample of available research, selectively. As evidence for Triple-P has constantly and substantially evolved over a 30 years' period. On the other hand, Triple-P system has five levels and the intensity of intervention increases at each level, respectively [22]. Therefore, it is important that to aware level one is universal screening and media-based parenting. This level is appropriate for families with little problems in the child rearing. The levels two and three are appropriate for families with more problems in the child rearing. In these levels were done brief intervention. The levels four and five were done interventions of family therapy and more intensive parent training. These levels are appropriate for families with severe problems in the child rearing or families with exceptional children. [35] It can be said Wilson P, et al. [35] paid few attentions or ignored to levels of Triple-p and problems in the families. So, there were many methodological issues in this meta-analysis research.

For explain the similar results with result of present research it can be stated that presence of a deaf or hard of hearing child may effect on access to support for the child, family resources, parenting style and family interaction [3]. Deaf children in comparison with normal children have more negative effect on interaction with parent [17]. In addition, parent of these children needs more comprehensive family therapy interventions and parenting programs [20]. In Triple-P training, parent trained about treatment and prediction of children difficulties which were discussed in group sessions, and mothers can have obtained the sufficient support and information. Also, mothers can find out the difficulties of their children via obtain to correct information, acquire the behavior control and management skills by appropriate training [36]. Therefore, it is expected to lead to decrease of conflict and dependency, and also increase of closeness and positive relationship of mother and deaf child.

\section{Limitations and future directions}

The present research has few limitations. It only included a low number of the mothers of male deaf children and only encompassed mothers aged 32 to 41 years that their children aged 8 to 10 years who have IQ between 90-100 and were in the second to fourth in exceptional schools. This research limited to special instrument for assessment of the interaction of mother-child. Also, due to time limitation, was not provided opportunity for follow-up.

It is suggested that next researches would be done for other exceptional children in different ages and different educational backgrounds. The other parenting interventions such as the parent-child interaction therapy, incredible year program and parent management training will be used, and the results will be compared. Also, would be considered opportunities for follow-up.

\section{Conclusion}

The presence a deaf child has a significant impact on life of family members, especially interaction of mother and deaf child, while use of Triple-P has been associated with desirable outcomes on promotion interaction of mother and deaf child, so planning for Triple-P intervention has special importance. Interaction of mother-child is a complex and multi-dimensional phenomenon that created through effect of the relation of main factors such as rate of acceptance and attitude of parent, behavioral management and control, parenting knowledge and skill, sense of social competency, quality of mother-child interaction, self-confidence, parent care from child, general health of parent, and interactional and multilayer relations parent-child. Therefore, attention to these factors is essential and plays an important role into interaction, conflict, closeness, dependency and relationship of mother-child. For this reason, if parent education program has a positive attitude toward child rearing and improve parenting skills, it will lead to improved relationships and interaction of mother and deaf child.

\section{Acknowledgements}

We would like to thank all mothers of deaf children for their participation in this study.

\section{Conflict of Interest}

No conflict of interest.

\section{References}

1. Fullana J, Pallisera M, Vilà M, Valls MJ, Díaz Garolera G (2019) Intellectual disability and independent living: Professionals' views via a Delphi study. J Intellect Disabil 23: 29-38.

2. Ashori M, Norouzi Gh, Jalil Abkenar SS (2019) The effect of positive parenting program on mental health in mothers of children with intellectual disability. J Intellect Disabil 23: 1-15

3. Antonopoulou K, Hadjikakou K, Stampoltzis A, Nicolaou N (2012) Parenting styles of mothers with deaf or hard-of-hearing children and hearing siblings. J Deaf Stud Deaf Educ 17(3): 306-318.

4. Szarkowski A, Brice P (2018) Positive psychology in research with the deaf community: An idea whose time has come. J Deaf Stud Deaf Educ 23(2): 111-117.

5. Barr M, Duncan J, Dally K (2018) A systematic review of services to DHH children in rural and remote regions. J Deaf Stud Deaf Educ 23(2): 118130 .

6. Broekhof E, Bos MGN, Camodeca M, Rieffe C (2018) Longitudinal associations between bullying and emotions in deaf and hard of hearing adolescents. J Deaf Stud Deaf Educ 23(1): 17-27.

7. Sanders MR, Kirby JN, Tellegen CL (2014) Towards a public health approach to parenting: A systematic review and meta-analysis of the Triple P-positive parenting program. Clin Psychol Rev 34(4): 337-357. 
8. Hallahan DP, Kauffman JM, Pullen PC (2018) Exceptional learners: An introduction to special education, USA.

9. Rudner M, Seeto M, Keidser G, Johnson B, Rönnberga J (2019) Poorer speech reception threshold in noise Is associated with lower brain volume in auditory and cognitive processing regions. J Speech Lang Hear Res 62(4S): 1117-1130.

10. Ashori M, Jalil Abkenar SS (2019) The effectiveness of cognitive rehabilitation program on auditory perception and verbal intelligibility of deaf children. Am J Otolaryngol 40: 693-702.

11. Zaidman Zait A, Most T, Tarrasch R, Haddad eid E, Brand D (2016) The impact of childhood hearing loss on the family: Mothers' and fathers' stress and coping resources. J Deaf Stud Deaf Educ 21(1): 23-33.

12. Shin HY, Hwang HJ (2017) Mental health of the people with hearing impairment in Korea: A population-based cross-sectional study. Korean J Fam Med 38(2): 57-63.

13. Lawyer G (2018) Deaf education and deaf culture: Lessons from Latin America. American Annals of the Deaf; 162(5): 486-488

14. Kirk S, Gallagher G, Coleman MR (2015) Educating Exceptional Children $14^{\text {th }}(\mathrm{edn})$. Cengage Learning, USA.

15. Batten G, Oakes PM, Alexander T (2014) Factors associated with socia interactions between deaf children and their hearing peers: A systematic literature review. J Deaf Stud Deaf Educ 19(3): 285-302.

16. Granqvist P, Sroufe LA, Dozier M (2017) Disorganized attachment in infancy: A review of the phenomenon and its implications for clinicians and policy makers. Attach Hum Dev 19(6): 534-558.

17. Crettenden A, Lam J, Denson L (2018) Grandparent support of mothers caring for a child with a disability: Impacts for maternal mental health. Research in Developmental Disabilities 76: 35-45.

18. Koolen J, van Oorsouw W, Verharen L, Embregts P (2019) Support needs of parents with intellectual disabilities: Systematic review on the perceptions of parents and professionals. J Intellect Disabil 23: 53-64.

19. Kabasakal E, Özcebe H, Arslan U (2019) Are the health needs of children with disabilities being met at primary schools? J Intellect Disabil 23.

20. Feniger Schaal R, Joels T (2018) Attachment quality of children with intellectual disability and its link to maternal sensitivity and structuring Res Dev Disabil 76: 56-64.

21. Fujiwara T, Kato N, Matthew R (2011) Effectiveness of group positive parenting program (triple $\mathrm{p}$ ) in changing child behavior, parenting style, and parental adjustment: An intervention study in Japan. Journal of Child and Family Studies 20(6): 804-813.

22. Ruane A, Carr A (2018) Systematic review and meta-analysis of steppingstones Triple P for parents of children with disabilities. Family Process 58(1):232-246.

23. Kleefman M, Jansen DEMC, Stewart RE (2014) The effectiveness of steppingstones Triple $\mathrm{P}$ parenting support in parents of children with borderline to mild intellectual disability and psychosocial problems: a randomized controlled trial. BMC Med 12: 191.

24. Sanders MR (2012) Development, evaluation, and multinational dissemination of the Triple P-positive parenting program. Annul Rev Clin Psychol 8: 345-379.

25. Sanders MR, Pickering JA, Kirby JN (2012) A commentary on evidencedbased parenting programs: redressing misconceptions of the empirical support for Triple P. BMC Med10: 145.

26. Schappin R, de Graaf IM, Reijneveld SA (2017) Effectiviteit van Triple P in Nederland: stand van zaken en controverse. Kind en adolescent 38(2): $75-90$

27. Lohan A, Mitchell AE, Filus A (2016) Positive parenting for healthy living (Triple P) for parents of children with type 1 diabetes: Protocol of a randomised controlled trial. BMC Pediatr 16(1): 158.

28. Marschark M, Lampropoulou V, Skordilis EK (2016) Diversity in deaf education (Perspectives on Deafness), USA

29. Moeller MP, Ertmer DJ, Stoel Gammon CS (2016) Promoting language and literacy in children who are deaf and hard or hearing. Paul $\mathrm{H}$ Brookes Publishing Co, USA.

30. Rostami M, Younesi SJ, Movallali G, Farhood D, Biglarian A (2014) The effectiveness of mental rehabilitation based on positive thinking skills training on increasing happiness in hearing impaired adolescents. Auditory and Vestibular Research 23(3): 39-45.

31. Glazemakers I, Deboutte D (2013) Modifying the positive parenting program for parents with intellectual disabilities. J Intellect Disabil Res 57(7): 616-626.

32. Chu J, Farruggia S, Sanders MR (2012) Towards a public health approach to parenting programs for parents of adolescents. Iran J Public Health 34(1): 41-47.

33. Metzler C, Sanders MR, Rusby J (2012) Using consumer preference information to increase the reach and impact of media-based parenting interventions in a public health approach to parenting support. Behav Ther 43(2): 257-270.

34. M, Afrooz GA, Arjmandnia AA, Pourmohamadreza Tajrishi M, Ghobari Bonab B et al. (2019) Adaptation of positive parenting program training based on cultural values and evaluation of its effectiveness in psychological health and interaction of mother with slow paced children. J Research Health 9: 284-293.

35. Wilson P, Rush R, Hussey S (2012) How evidence-based is an 'evidencebased parenting program'? A PRISMA systematic review and metaanalysis of Triple P. BMC Med 10: 130.

36. Sanders MR (2008) Triple p-positive parenting program as a public health approach to strengthening parenting. J Fam Psychol 22(4): 506517. 